\title{
Implementation of Distributed Hydrological Modeling in a Semi-Arid Mediterranean Catchment Azzaba, Morocco
}

\author{
Bouadila Abdelmounim ${ }^{1 *}$, Lahcen Benaabidate', \\ Ismail Bouizrou', Mourad Aqnouy² \\ 1 Laboratory of Georesources and Environment, Faculty of Sciences and Technology, USMBA, PO Box 2202, \\ Route d'Imouzzer, 30000 Fez, Morocco \\ 2 Laboratory of Geology and Oceanology, Faculty of sciences Tétouan, Abdelmalek Essaadi University, \\ Mhannech II. B.P. 2121, 93002 Tétouan, Morocco \\ * Corresponding author's e-mail: abdelmounim.bouadila@usmba.ac.ma
}

\begin{abstract}
The typical Mediterranean climate is marked at certain times of the year by sudden torrential rains causing high water flows, which leads to heavy flooding and hydroclimatic fluctuations due to a semi-arid climate. This explains the need for hydrological modeling for water resource management in these contexts. This work concerns the hydrological modeling of the Azzaba catchment area in Haut-Sebou "Morocco". In the first part of this work, a bibliographic synthesis was carried out to characterize certain factors (physical, geological and climatic), and a hydrological study was carried out by processing rainfall and hydrometric data from the considered time periods. Ultimately, the use of the "ATHYS" platform is beginning to reproduce the flows at the Azzaba outlet. This model is really applicable in the semi-arid context based on several studies carried out on these contexts, since it has to consider the chronological sequence of phenomena on one hand and the influence of the climatic and physicalhydrogeological parameters of the basin (humidity and soil exchange) on the other. Several criteria were used in this study to estimate the model performance; the most common is Nash-Sutcliffe. After observation and analysis of the overall results, it can be concluded that the model reproduces flows in the Azzaba River watershed well, especially in event mode (mean Nash-Sutcliffe value of 0.71 ). The use of a historical meteorological time series to simulate flow using a daily time step gives average results with a Nash of 0.50 , which strengthens the reliability of the ATHYS platform in the Mediterranean climate area.
\end{abstract}

Keywords: semi-arid mediterranean context; flood forecasting; continuous modeling; event-based modeling; ATHYS platform; distributed SCS-LR model.

\section{INTRODUCTION}

In the Mediterranean context, particularly in Morocco, where small river basins and ephemeral streams are common, flash floods are very destructive phenomena and are caused by intense rainfall causing short periods of flooding, usually lasting several hours capable of causing significant socio-economic damages. Specifically, flash flood waves move at very high speed and can reach heights of a few centimeters to a few meters (Archer et al. 1992). These flood wave characteristics can destroy structures and tear up trees, causing severe damages.
For hydrological operational needs such as flood forecasting, a good knowledge of precipitation is essential in the case of flood events. Andreassian et al. 2001 or Wagener et al. 2007 showed how crucial it is to test the sensitivity of rainfallrunoff models to different rainfall inputs in order to assess their sensitivity and robustness. The modeling of flood events is strongly influenced by rainfall characteristics, in particular the spatial distribution of precipitation and its intensity (Andréassian et al. 2004; Saulnier and Le Lay 2009).

Morocco is often confronted with serious rainfall events that can cause catastrophic floods, more precisely these phenomena are 
remarkable at the Azzaba watershed which is the subject of this study, and cause considerable damage. Thus, the simulation of flows at the outlet of this catchment is relevant in order to cope with the increase and vulnerability of flood risks. Generally, hydrological models can be used in various projects such as floodplain management or more specifically flood protection, especially in the areas strongly influenced by these natural phenomena and also other applications in water resource management fields (Singh and Woolhiser 2002).

Several reasons justify the choice of using the ATHYS platform for rainfall-runoff modeling. The distributed nature of this model enables to take into account the strong spatio-temporal variability of the physical characteristics of the watershed, as this model adapts to the semi-arid Mediterranean regions, and works for both continuous and event modes. Furthermore, for the spatially complex watersheds or the ones with a very large surface area, the use of discrete hydrological models based on numerical terrain models is preferable for hydrological modeling (Endreny et al. 2000). Several reasons restrict the use of these distributed models in a wide range of watersheds, especially in developing countries, these reasons include very high calculation costs and a large number of data requirements that are not available in most cases.

Event-based models have several advantages over continuous models and are often preferred for real-time and operational applications (Berthet et al., 2009). They only require eventscale data and avoid the use of complete time series. They are also easier to calibrate, since they only take into account the event-scale flooding processes, and therefore require fewer parameters. The main disadvantage is that the initial conditions must be defined from additional external information. As such, the number of soil conservation service curves (SCS-CN) method is very popular and has been widely used because of its simplicity. This model incorporates an empirical method for estimating previous moisture conditions (AMC) using three levels of AMC - dry, average, wet - based on the amount of rainfall in the last 5 days (Mishra and Singh, 2003). It was also noted that flash flood studies often face the obstacles related to the absence of fine scale climate data, such as hourly and/or infra-hourly precipitation; this is consistent with the study conducted by (Gaume et al. 2004).
Continuous mode modeling uses the daily time step to better understand the hydrological behavior of the watershed, including rapid changes in flows after summer thunderstorms and the determination of dam inflows. The use of the daily time step also enables to compare the calculated flows with the point gauges of the rivers.

In this study, the SCS-CN model was used as a production function because this model is very flexible, and also capable of adapting to different types of flood formation processes. Thus, the Lag \& Route model was used as a transfer function, their choice is explained by the desire to obtain both a global model of the contribution of the various parameters (losses, runoff, etc.) and precision by choosing to know this contribution for each mesh independently of the others.

\section{METHODOLOGY}

\section{Study area}

The Sebou watershed with an area of 40000 $\mathrm{km}^{2}$ drains about 1/3 of Morocco's surface runoff. This basin is attributed to the Middle Atlas, often called "water tower" of Morocco because of its heavy rainfall and its large number of springs. In addition, the Sebou catchment area, populated by 5.9 million inhabitants, is one of the richest regions in water and is one of the best endowed ones in irrigated land and industries. The potential for cultivated land is $1,750,000$ ha. The irrigable areas are estimated at 375,000 ha, of which 269,600 are currently irrigated. The upstream basin, which is the subject of this work, drains about $10 \%$ of Morocco's runoff in an average year over an area of $4677 \mathrm{~km}^{2}$ at the Azzaba station (Figure 1). It is located in the Middle Northern Atlas Mountains between latitudes $33^{\circ}$ and $34^{\circ}$ North and longitude $4^{\circ} 03^{\prime \prime}$ and $5^{\circ} 20^{\prime \prime}$ West. This basin is drained by the Sebou wadi which originates in the region of Aguelmane Sidi Ali at the altitude of about 2078 $\mathrm{m}$. On its course, the Sebou river receives several tributaries (Guigou, Zloul, Maasser, etc.) dug mainly as the main course in the Jurassic carbonate soils (calcareous and dolomite) the elevations of which locally exceed $2500 \mathrm{~m}$ above sea level.

It should be recalled that the position of the Middle Atlas has attracted the attention of many researchers in various specialties (including hydrology, history, geology, geomorphology, etc.), due to the wealth of natural resources and the importance of rainfall which falls in the great 


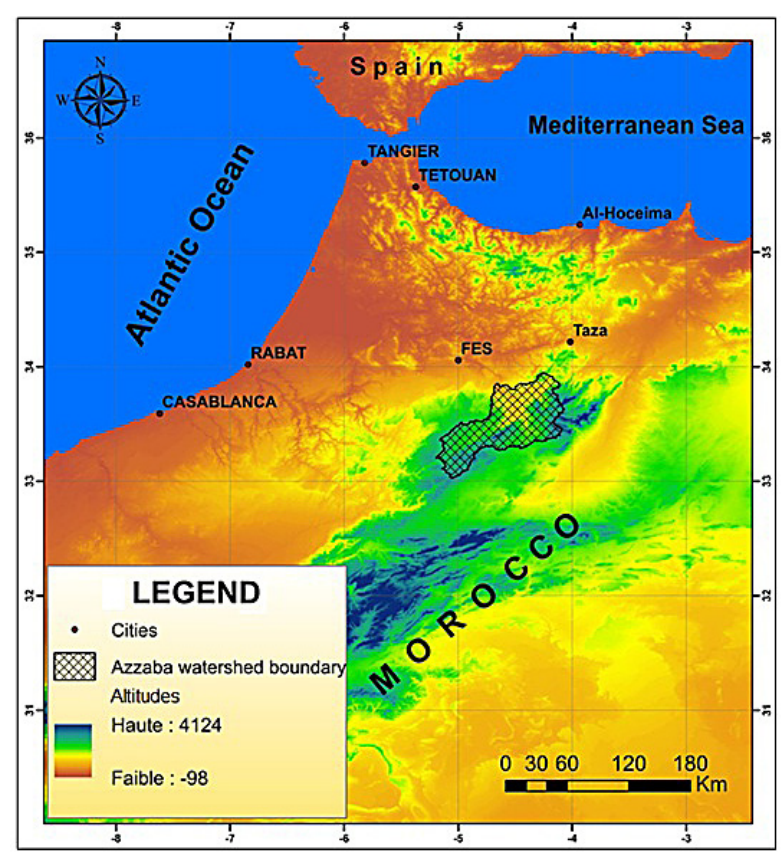

Figure 1. The location of the Azzaba watershed "high Sebou, Morocco"

altitudes that characterize it, and causing floods and catastrophic inundation from time to time. The land use patterns in this watershed, which is characterized by a fairly remarkable diversity (Figure. 2have a major impact on the hydrological functioning of the Azzaba watershed.

\section{Hydrologic modeling overview}

Modeling is a tool designed to represent a simplified version of reality (hydrological cycle) through a set of mathematical equations to understand the hydrological behavior and efficiently manage the water resources in watersheds. Typically, hydrological models require input data such as precipitation, evapotranspiration, etc, to obtain flow rates as output, so these models use the same watershed operation (Figure 2).

The modeling of the hydrological behavior of watersheds is unavoidable when one is interested in the issues relating to the management of water resources and regional planning, or to one of the different facets of hydrological risks. It must be able to write the different stages of the rainfallrunoff transformation and in particular the processes related to the formation of floods and the appearance of low water. It is also supposed to provide usable information on the design of hydraulic structures, flood protection and the hydrological and ecological management of watersheds (Vannier et al. 2014).

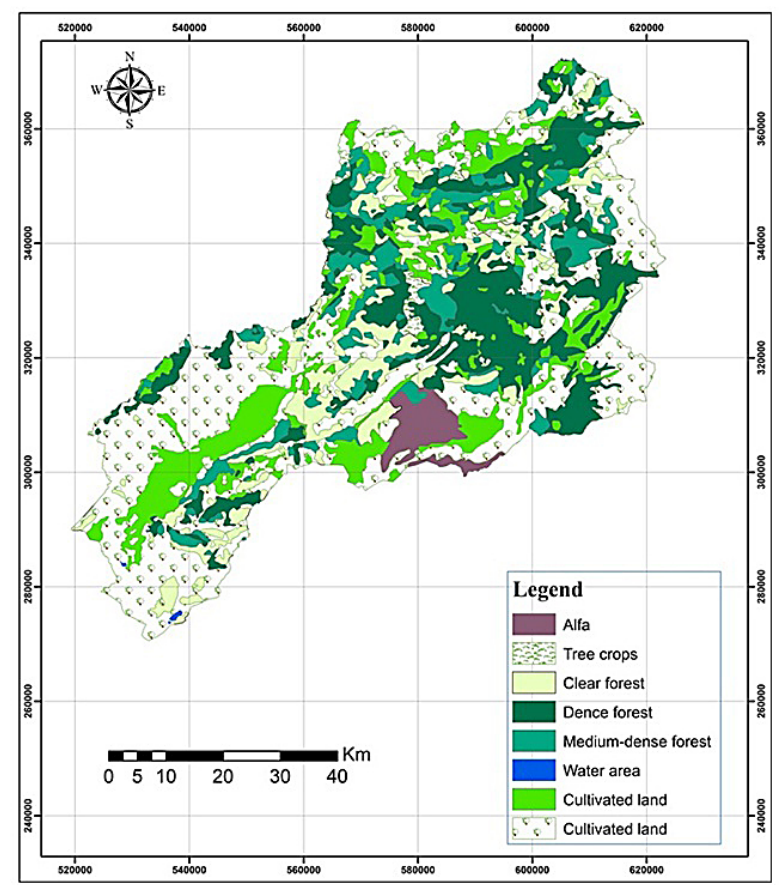

Figure 2. Land use of the Azzaba watershed

\section{Hydrological modeling objectives}

Our study consisted in using the ATHYS hydrological model for the reproduction of floods at the Azzaba catchment; more precisely, the first phase of this study was carried out by using hourly data to restore the different historical floods in this watershed, secondly multi-year data series were used to elaborate a hydrological model in continuous mode (daily time step). The model concept generally links a system, which constitutes the reality to be modeled, and its representation. For example, in the case of the models that transform rainfall into runoff, an illustration was provided to better understand the general principle of this modeling (Figure 3).

Rainfall-runoff modeling can provide the answer to many water-related questions that focus on resource and risk management:

- The reconstitution of hydro-rainfall datasets by filling the gaps in the historical series more precisely by means of extrapolation in time and interpolation in the space of the hydrological variables in order to allow the statistical treatments used in particular in the feasibility studies works and determination of project values.

- Prediction of the frequencies with which the extreme flows (flood and low water) can appear.

- Predetermination of the hydrological response of a watershed with a time step, to allow the development of a system of prevention and alarm. 


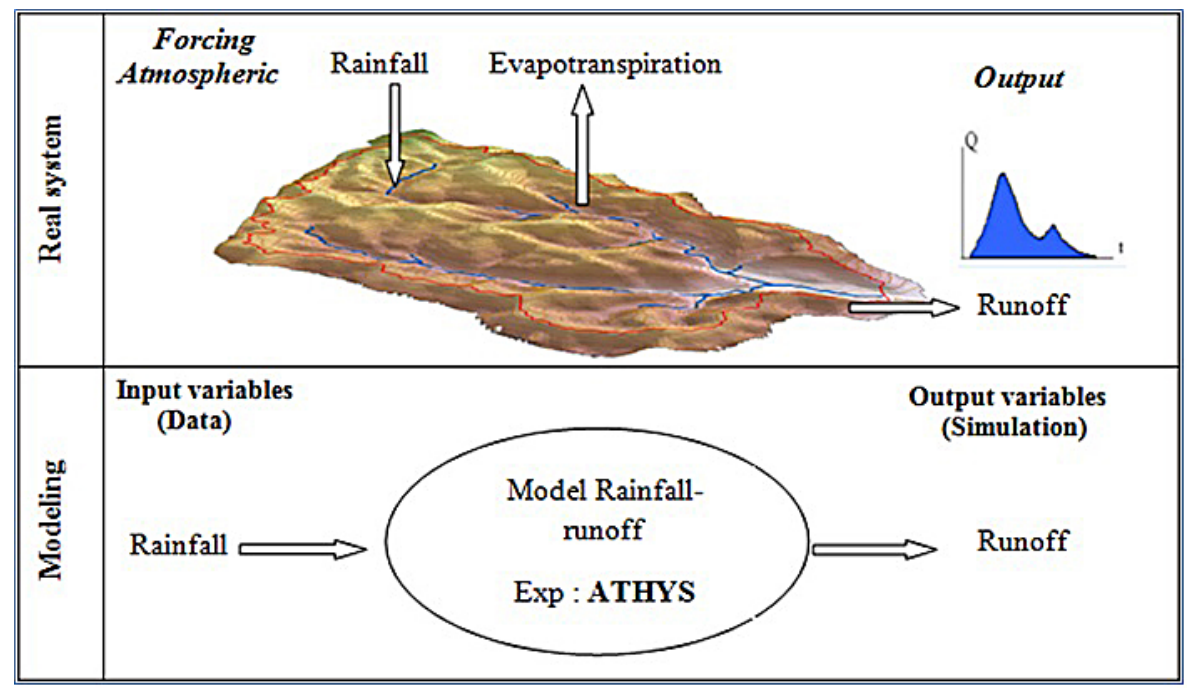

Figure 3. Schematic representation of rainfall-runoff modeling

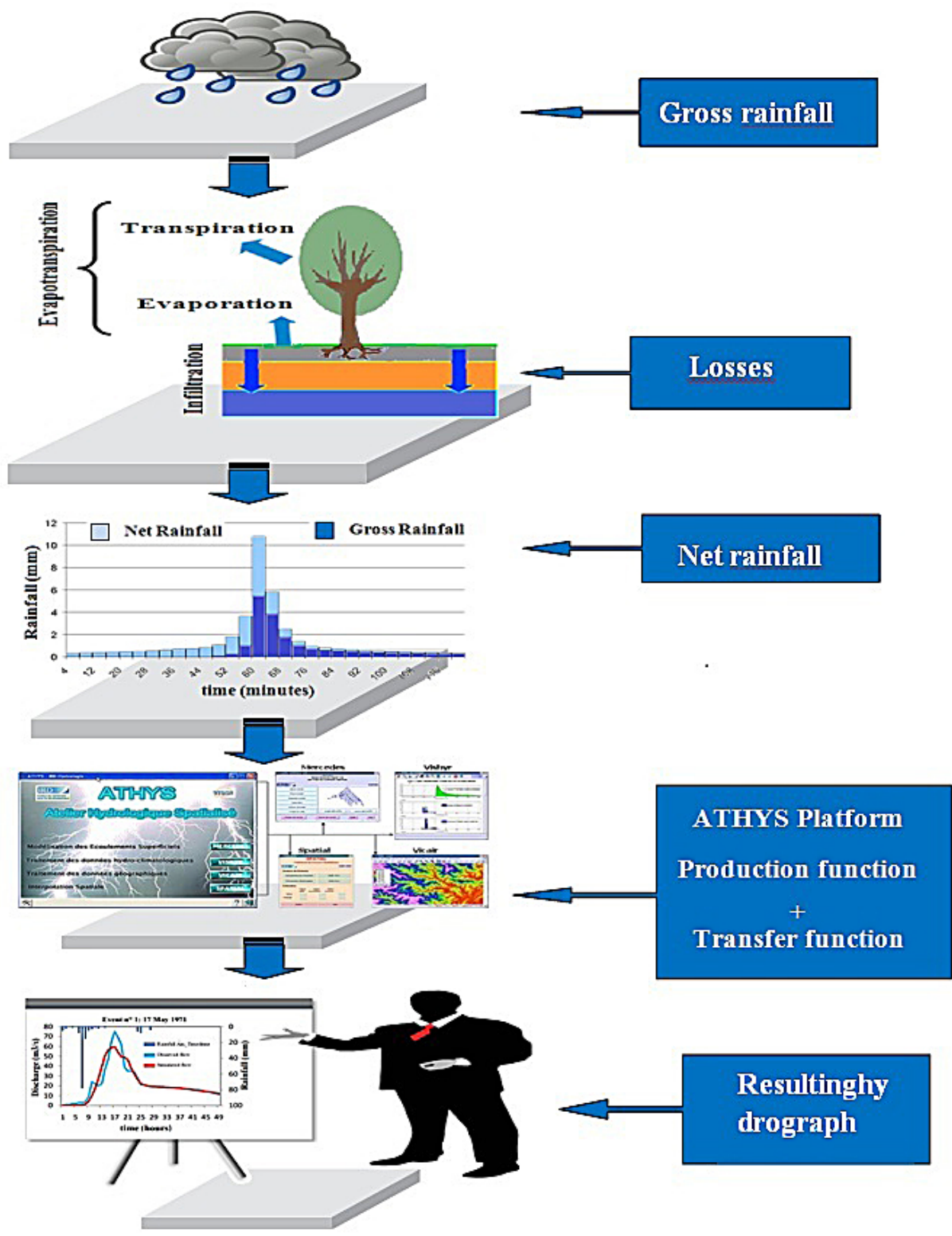

Figure 4. Schematic representation of the "ATHYS" rainfall-runoff transformation model 
- The study on the impact of different developments on the hydrological response.

- Improvement of knowledge on the hydrological systems based on observations of their behavior, thus enabling to consider the inventory of water resources.

- Transfer of information from one site to another through simulation.

\section{Hydrological modeling steps}

For a very satisfactory and representative hydrological modeling, it must of course respect certain essential steps:

1) Define: the model and its objectives in terms of precision. This definition will enable to determine the choices to be made subsequently and thus to specify the paths to follow in the other stages.

2) Identify: the model, in order to define and characterize the system, its boundaries and structure; define the event, variables and parameters; and make assumptions and choices of time and space scales characteristic of the basic processes.

3) Calibrate: the model, by estimating the parameters of the model, which cannot be measured in the field, according to deductive criteria or observations of inputs and outputs. The calibration can be manual, i.e. by the use of a sensitivity analysis, or automatic, i.e. the parameters are defined automatically by the model.

4) Evaluate: the model, by comparing the simulated response to the real or observed response in the measurement stations, the criterion most commonly used for determining the difference between the two variables compared is that of Nash-Sutcliffe.

5) Validate: The validation of the model or the verification of the parameters is a continuation and an essential complement to the calibration step. It consists in testing whether the model is able to simulate the behavior of the system by using a series of input data other than that with which it was identified. Generally, there are many methods to validate the model but the most commonly used one involves calculating averages of the parameters already acquired in the calibration stage and using them automatically; finally, if the results obtained are very efficient, we can say that this model is relevant to the studied area.

\section{Criteria for choosing the ATHYS hydrological model}

The complexity of the zone type and the large area on which we focus, requires the use of a distributed model and this is the case for the ATHYS. In this work, we are not only trying to reproduce flood hydrographs at best, but also to maximize a simulation quality criterion in our study area as well as to reproduce the various components of the flow as realistically as possible and to make them available. Moreover, the choice of this hydrological model is justified by the fact that this model allows us to analyze the different types of flow (surface flow, deep flow, point flow and base flow), and for a better analysis of these characteristics, the distributed conceptual models are preferable (Kampf and Burges 2007). More precisely, the ATHYS hydrological model choice is made according to the following elements:

- The importance of the area of the basin and the diversity of reliefs, type of soils and their occupation: the Azzaba watershed has an area of $4677 \mathrm{~km}^{2}$ and is also characterized by a large diversity of reliefs which requires the use of a distributed model, this principle is combined with spatialization of the rainfall data, which allows to take into account the spatial variation of rainfall intensities on large watersheds like in the considered case.

- The objectives of the hydrological study: The aim of this study is flood forecasting, so it is necessary to use the software that works with both time steps, i.e. the daily and the hourly, and is the case of ATHYS, to carry out the modeling in both continuous and event modes.

- Availability of data: Always the availability of data forces us to use certain models; sometimes it is very difficult to find data for the elaboration of an event-driven modeling, especially in hourly time steps; thus, the users are oriented towards the platforms using daily data as inputs. In our case, the data are available in daily and hourly time steps, despite the existence of gaps in these, and after several analyses and the use of methods filling these gaps such as linear interpolation and extrapolation methods, the data become more and more representative.

- Model nature: the choice of ATHYS platform is based on their robustness and their applicability on the semi-arid regions, but like most 
models, ATHYS has certain drawbacks such as the long elapsed time to run the model and obtain the simulated results, so the user really needs a long time to calibrate a rainy episode, especially in the case of manual calibration.

\section{BREIF MODEL DESCIPTION}

\section{General structure of ATHYS platform}

- L'Atelier Hydrologique Spatialisé "ATHYS": Is a rainfall-runoff model which gathers a set of specialized hydrological models associated with hydroclimatic and geographical data processing. This software lends itself to various applications: management of water resources, prediction of extreme events, impact studies related to anthropogenic or climatic modifications. It consists of four modules (Figure 4):

- MERCEDES (Maillage Elémentaire Régulier Carré pour l'Etude des Ecoulements Superficiels): is a conceptual spatialized model operating on the basis of regular square meshes, to represent the superficial flows from the knowledge of the main factors that can influence the flow such as the reliefs (Bouvier et al. 1994). This module can also be used to calculate the amounts of precipitation produced by each mesh in each time step more precisely using the Thiessen method, and these contributions are routed directly to the watershed outlet by using a routing model (Lhomme et al. 2004) which forms part of the city of Quito (Ecuador.

- VISHYR (Visualisation des données Hydrologiques): it is a module used for conversion, visualization as well as the treatment of hydro-climatic data before use in MERCEDES.

- VICAIR (Visualisation des Cartes et Images Raster): This module is generally used to superimpose maps and subsequently to check their consistency (Bouvier and Delclaux, 1996). This module can also be used to carry out other operations such as correcting DEM files by eliminating some depression and looping in the original file, as well as converting formats of digital terrain models and creating drainage files that allow the user to delimit the basin and recognize the spatialization of the hydrographic network in the watershed under study.

- SPATIAL: Spatial interpolation platform and is under development.
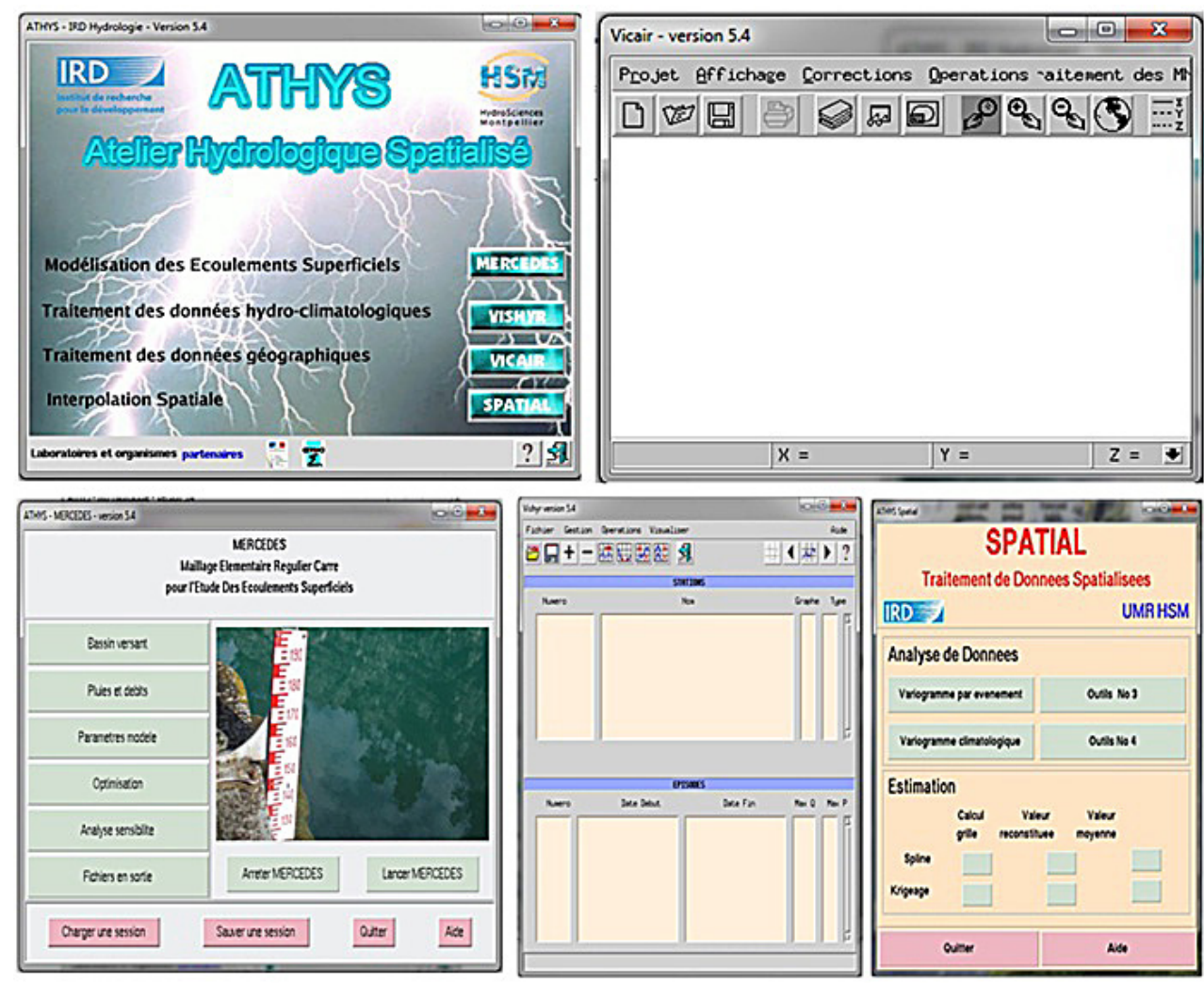

Figure 5. Main interface of ATHYS and its 4 modules (source: IRD) 
Generally, the coupling of distributed hydrological models with GIS can allow the processing of spatial data such as digital elevation models and also a multitude of geomorphological maps, in order to offer a very efficient use of spatially distributed data to better analyze finally the hydrological processes of the studied areas (Orlandini and Rosso, 1996). The main interest of the ATHYS platform is the possibility of spatializing the rainfall-runoff transformation. Indeed, the model uses a digital elevation model (DEM) as input to compute the mesh flow, mesh by mesh. This principle is combined with a spatialization of rainfall data, which allows large watersheds to take into account the spatial variation of rainfall intensities.

\section{Choice of a production and transfer model}

The ATHYS model, like most hydrological models, allows us to transform the series of climatic data "precipitation" into runoff, following two essential parts to best describe the flow of water towards the outlet of the watershed:

\section{The production function "SCS-CN"}

The hydrological model "ATHYS" is a distributed model, whereas the production function allows us to determine the quantity of water that will contribute to the runoff mesh by mesh, by taking into account the fractions of water stored in the surface reservoirs, either natural or artificial (lakes, dams, etc.), or the quantities of water lost by various natural phenomena such as infiltration to achieve water storage in soil reservoirs, in order to finally obtain a net contribution that will participate in the runoff of the studied basin. In MERCEDES, there are seven production functions: Reservoir-1, Reservoir-2, Girard, GreenAmpt, Smith-Parlange, Top-Model and SCS-CN.

The SCS-CN model developed by Soil conservation service (SCS, 1956) was used in this study. The choice of this model is explained by their tendency to link the net rainfall (the fraction of precipitation that contributes to the rutting) to the gross rainfall (the total rainfall that fell in the watershed and measured by one or more rain gauges) according to the following equation

$$
\mathbf{P}_{\mathbf{e}}=\frac{(\mathbf{P b}-\mathbf{I a})^{2}}{(\mathbf{P b}-\mathbf{I a})+\mathbf{S}}
$$

where: $\mathrm{Pe}-\mathrm{Net}$ precipitation at time $\mathrm{t}$;

$\mathrm{Pb}-$ The gross precipitation at time $\mathrm{t}$;

Ia - losses occurring at the beginning of the event;
$\mathrm{S}$ - water retention capacity of the soil.

All these parameters are expressed in $\mathrm{mm}$.

After carrying out numerous experiments, the Natural resource conservation service "NRCS" proposed an additional empirical relationship linking the initial abstraction Ia of a catchment to the water retention capacity of soil S:

$$
\mathrm{Ia}=\mathbf{0 . 2} * \boldsymbol{S}
$$

Thus, the equation becomes:

$$
\mathbf{P e}=\frac{(\mathbf{P b}-0.25)^{2}}{\mathrm{~Pb}+0.85}
$$

The diagram has been completed in MERCEDES with a ground tank to take into account the emptying of the soil (see Figure 5). The reservoir is supplied by the water that seeps in, and is drained by the evaporatory recovery; the percolation to the deep groundwater and the exfiltered water are returned to gravity flow.

In our case, i.e. during periods of flooding, the evaporation recovery is negligible compared to other processes. The modeling of this reservoir takes into account the initial state of the soil when several rainfall events occur.

The SCS-CN model on ATHYS consists of three parameters which are as follows:

- $\mathrm{S}$ (in $\mathrm{mm}$ ): Represent the maximum retention of ground reservoir, and according to Tramblay et al. 2011, this parameter can also be defined as the initial water shortfall at the beginning of each rain event. Generally, this capacity depends on many characteristics of the soil (heterogeneity, depth, porosity, hydraulic conductivity, etc.).

- Ds: is the coefficient of the exponential emptying of the soil tank (evaporation, hypodermic runoff, percolation, etc.). A value of 1 leads to a daily emptying rate of $63 \%(=1-\exp (-1))$ and to an emptying hourly rate of $4 \%$ (= 1 -exp $(-1 / 24)$ ). The values of $\mathrm{dS}$ are between 0 (no emptying) and $\infty$ (complete emptying of the tank) expressed in $\mathrm{d}-1$.

- w: Represent the fraction of drainage participates in the runoff as exfiltration.

Note well: For flood peaks, the most sensitive parameter of the production function is the capacity of the reservoir "S", which strongly influences the general appearance of these peaks, whereas the other parameters "ds, and w" are very little variables. 


\section{The transfer function "Lag and route"}

The Lag and route routing transfer function has been widely used (Bentura and Michel 1997) since this function plays an important role in the transformation of precipitation into runoff, and also allows the transfer of water quantities, already determined by the production function mesh by mesh directly to the outlet. There are two different modes of transfer functions in MERCEDES:

- The transfer in the interactive mesh mode: the transfer is carried out from one mesh to another, from upstream to downstream, taking into account the contributions of the upstream meshes and the possible losses at the level of the river beds. This model is the kinematic wave model.

- Transfer in the independent mesh mode: The contribution of each mesh is transferred entirely to the outlet without taking into account the contributions of the neighbouring meshes and the possible losses in the river beds. This is the Lag \& Route model, which is used in this study.

Usually, the criteria used for choosing this model are mainly their simplicity when calibrating the model, especially in the cases where a manual calibration is used to estimate the optimal parameters, and also the Lag and Route model contains only two parameters that are the following:

- Vo: Is the maximum speed reached at the outlet during the event, expressed in $\mathrm{m} / \mathrm{s}$.

- $\mathbf{K}_{\mathbf{0}}$ (dimensionless): Is the depreciation parameter; experiments show that the parameter can therefore be empirically set at $\mathrm{K}_{0}=0.7$.

\section{Application of the coupled SCS-LR model in the Azzaba watershed}

Typically, for quantification of the total hydrograph of the flood generated by our basin, two essential steps must be followed when modeling the rainfall runoff:

The first part concerns the vertical flow of water, the main phenomena of which are rainfall, snowmelt, evapotranspiration, infiltration and changes in surface and deep reservoirs. This first part is referred to as the ,production function" and is calculated on each whole tile. Generally for a distributed model, surface runoff is generated by excess precipitation over all the meshes that touch the watershed surface, while total runoff is considered as the sum of surface and subsurface runoff (Ciarapica and Todini 2002)thus converting the original differential equation into a nonlinear reservoir equation based upon physically meaningful parameters, the solution of which can be found numerically. The catchment behaviour is finally obtained by aggregating the non-linear reservoirs into three cascades, representing the soil, the surface and the drainage network, following the topographic and geomorphologic elements of the catchment. The main advantage of this approach lies in its capability of being applied at increasing spatial scales without losing the physical interpretation of the model and parameters. Other advantages of the TOPKAPI approach can be found in the full use of the digital elevation model, soil maps, land-use maps, etc., for the derivation of the non-linear reservoir cascade and for the estimate of the model parameters. This allows for the extension of the model to ungauged catchments and as a promising tool for the impact assessment of climatic as well as landuse changes. Three case-studies are presented, showing the model application to catchments that are different in nature and size (from a few to over a thousand square kilometres.

Figure 6 explains the general principle of the SCS-CN production function applied in our watershed, so this function allows us to determine the

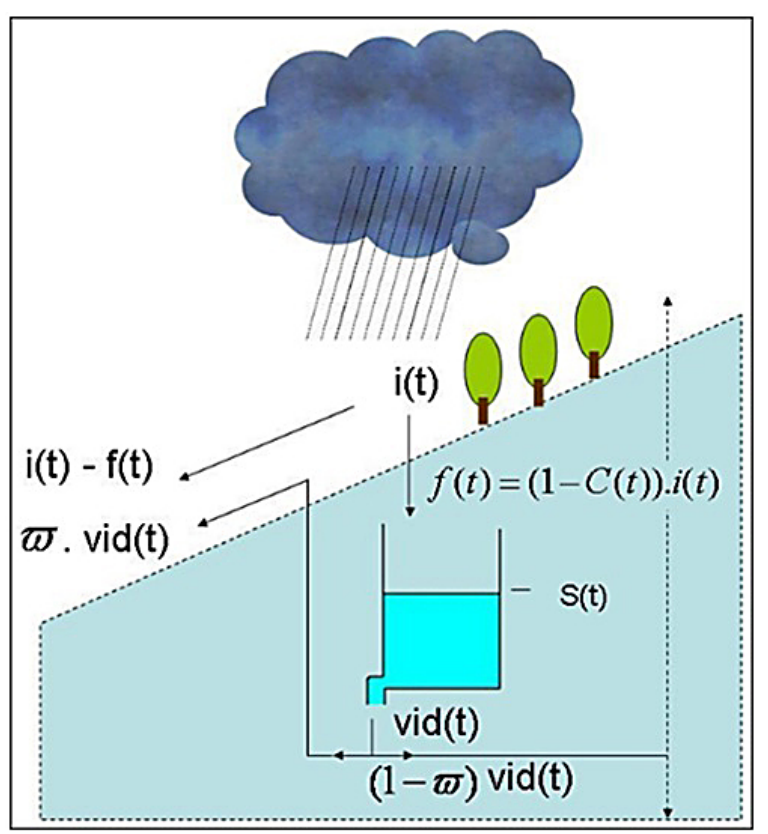

Figure 6. Principle of the SCS-CN production function (source: IRD) 
water balance in the watershed mesh by mesh, This is done by the distribution of gross rainfall (the total amount of rain falling in the basin) into net rainfall (the fraction of rainfall that contributes to runoff) taking into account the quantities of water extracted by the hydrological processes (Evapotranspiration, Infiltration, etc.), to finally quantify the total water balance at the outlet of our watershed.

The very large area of our watershed (4677 $\mathrm{km}^{2}$ ), is subdivided by the MERCEDES platform into 622201 regular square meshes to take into account the spatial variability of hydrological processes.

The second part concerns the transfer of the flow into the drainage system. The processes included in this section take into account the influence of lakes, swamps and man-made structures such as dams, diversions, etc. This part is referred to as the "Transfer function" and is carried out using partial tiles.

A very detailed explanation of the method of application of the "Lag and Route" transfer function in the basin studied is presented in Figure 7. After the discretization of the watershed area by the MERCEDES platform and the determination of the water slide which will contribute to the runoff mesh by mesh through the production function, the role of the transfer function comes to transfer these contributions to the outlet of our basin at each time step, and to produce a set of elementary hydrographs specific to the meshes that touch the surface of our study area, and these hydrographs are characterized by a shift in the general space and time, which is explained by the positioning of the meshes in relation to the outlet.

The transfer function "Lag \& Route" used in this study allows to transfer the contributions produced by all the meshes directly to the outlet of the watershed studied in the form of elementary hydrographs, and which represent the contributions of mesh by mesh in a separative way, i.e. without taking into account the inputs of neighboring meshes and the possible losses at the river beds; finally, these elementary hydrographs are summoned to obtain the complete hydrograph of the flood.

The "Lag and route" transfer function routes the total volumes it $(\mathrm{t})$ produced by each mesh to the catchment outlet. Then, these contributions arrive at the outlet after a propagation time $\mathrm{Tm}$ (the time elapsed between the rainfall falling on a mesh $m$ and the start of the event at the outlet) calculated from two following essential factors : the transfer velocity $\mathrm{Vm}(\mathrm{m} / \mathrm{s})$ and also the trajectory

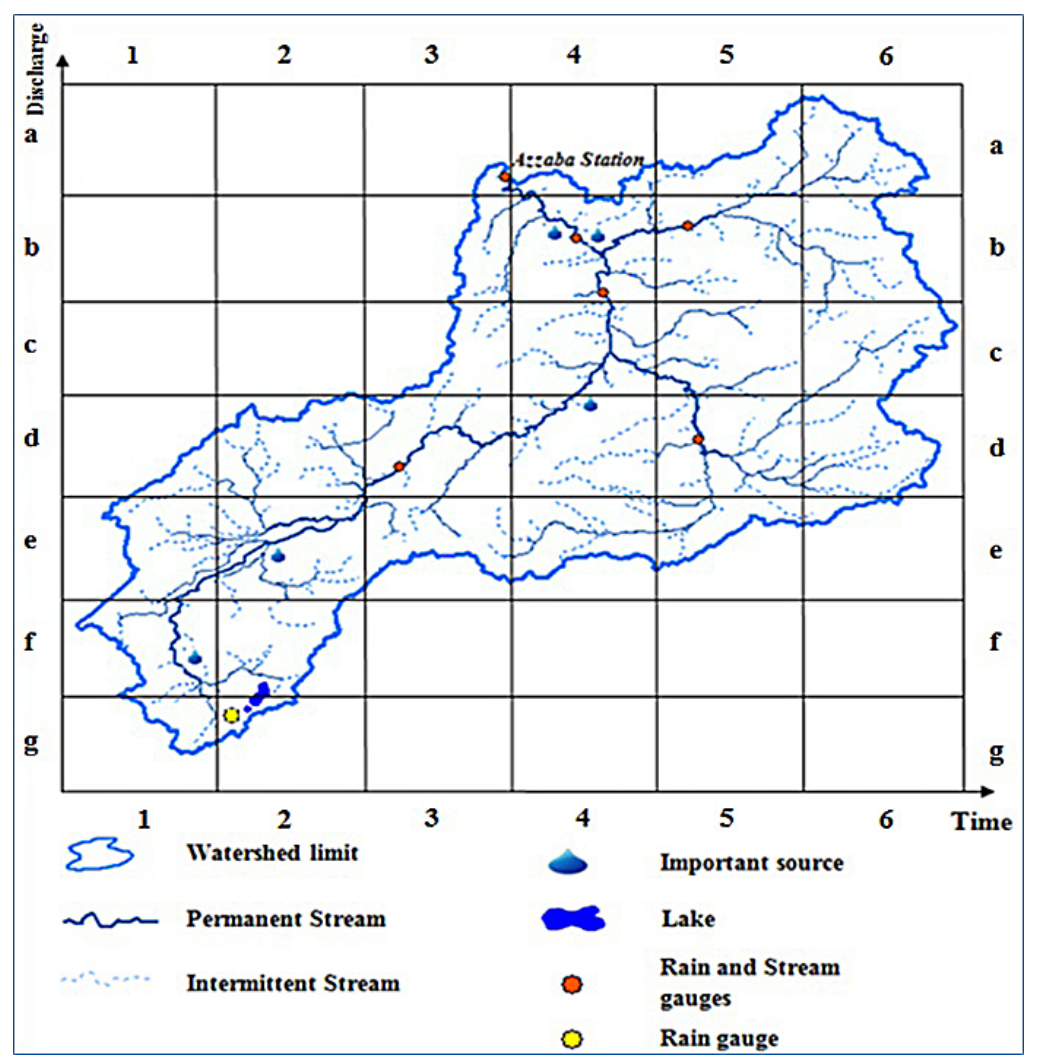

Figure 7 Creation of regular tiles by superimposing a grid on the watershed studied to calculate the contributions of each mesh "production function SCS-CN" 


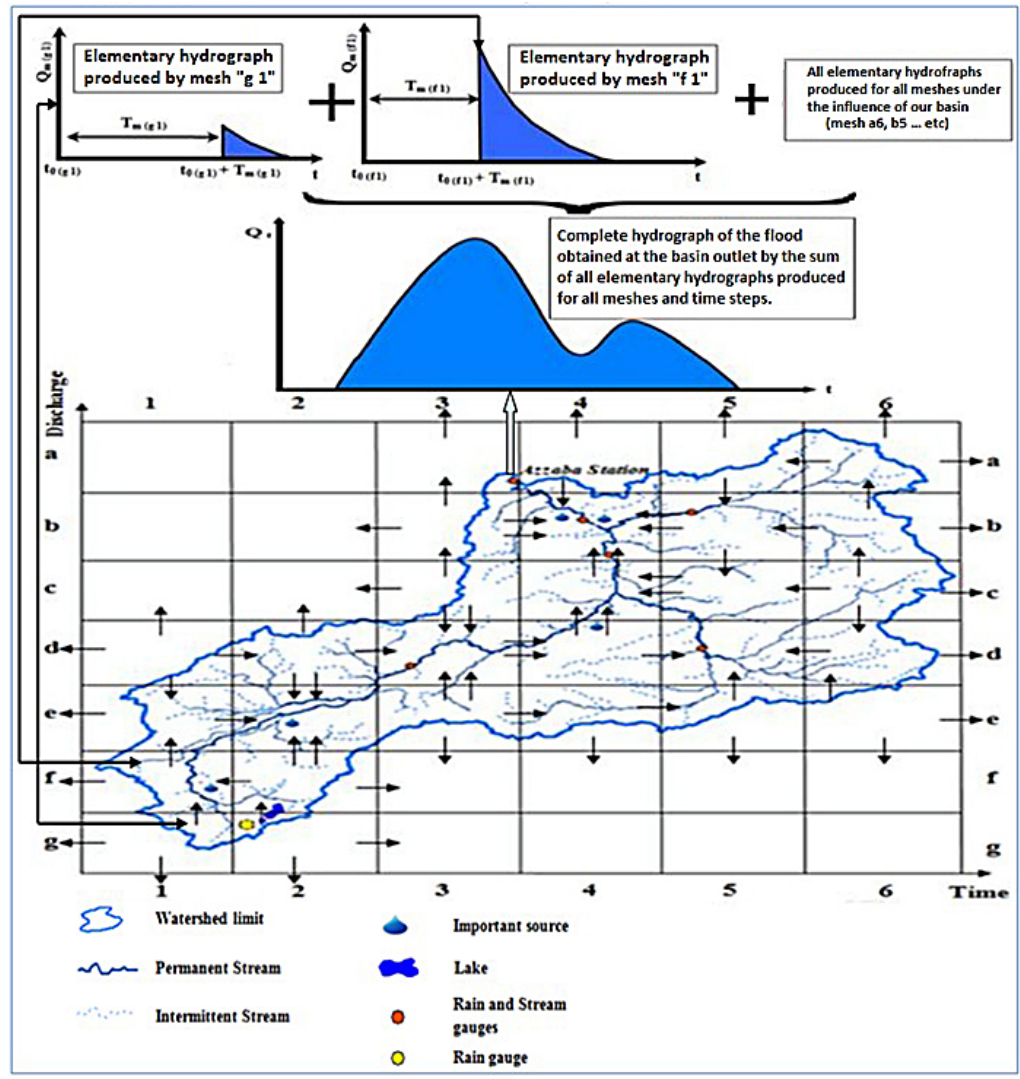

Figure 8. Explanatory diagram of the general principle of application of the "Lag and Route" transfer function on the studied basin

length Lm (m) between the m-mesh and the watershed outlet determined by the numerical terrain model used as model input, and the equation written as follows:

$$
\mathbf{T}_{\mathbf{m}}=\sum_{m=0}^{n} \frac{\mathbf{L}_{\mathbf{m}}}{\mathbf{V}_{\mathbf{m}}}
$$

where: Lm: is the distance travelled by the water in each mesh $m$ of the trajectory;

$\mathrm{Vm}$ : is the transfer speed between the mesh $\mathrm{m}$ and the pond outlet.

The contribution of the mesh $\mathrm{m}$ is also depreciated by applying the diffusion time Km (storage) proportional to the propagation time $\mathrm{Tm}$ (translation) which is calculated by the hydrological model on the basis of the digital elevation model, in order to deduce the flows corresponding to the contribution of this mesh at time $t$.

$$
\begin{gathered}
\mathbf{T}_{\mathbf{m}}=\frac{\mathbf{L}_{\mathbf{m}}}{\mathbf{V 0}} \\
\mathbf{K}_{\mathbf{m}}=\mathbf{K}_{\mathbf{0}} * \mathbf{T} \mathbf{m}
\end{gathered}
$$

The transfer function is therefore controlled by two parameters: $\mathrm{V}$ to adjust the propagation time Tm and $\mathrm{K} 0$ to adjust the broadcasting time $\mathrm{Km}$. The elementary hydrograph produced by each mesh at the basin outlet can then be calculated by:

$$
\begin{gathered}
\mathbf{Q}_{\mathbf{m}}(\mathbf{t})=\frac{\mathrm{i}_{\mathbf{t}}\left(\mathrm{t}_{0}\right)}{\mathbf{K m}} \cdot \exp \left(-\frac{\mathrm{t}-\left(\mathrm{t}_{\mathbf{0}}+\mathbf{T}_{\mathbf{m}}\right)}{\mathrm{Km}}\right) \cdot \mathbf{A} \\
\text { If } \mathrm{t}>\mathrm{t}_{0}+\mathrm{T}_{\mathrm{m}} \\
\text { If not } \mathbf{Q}_{\mathbf{m}}(\mathrm{t})=\mathbf{0}
\end{gathered}
$$

Where A designates the area of the mesh. The elementary contributions Qm ( $t$ ) of each mesh $\mathrm{m}$ are then added up to calculate the complete flood hydrograph:

$$
\mathbf{Q}_{\mathbf{t}}(\mathbf{t})=\sum_{m=0}^{n} \mathbf{Q}_{\mathbf{m}}(\mathbf{t})
$$

\section{RESULTS AND DISCUSSION}

\section{Calibration of the event mode:}

The calibration of the hydrological models is carried out to identify and recognize certain hydrological properties of the watershed. Indeed, the simplification of reality by estimating certain parameters that cannot be directly linked to field measurements requires calibration. Additionally, according to (Moriasi et al. 2007), during 
calibration the model parameters are estimated in the best possible way in order to compare results obtained as an output with punctual measurements at stream gauge (observed flow rates).

In the first phase of this study, a manual errortest calibration of different parameter values was used, and after obtaining optimal parameters, an automatic calibration was also used to improve the quality of our performance criteria for 14 flood episodes that are available between 1981 and 1996. The first seven events are used to calibrate the model and better reproduce these flood episodes at the Azzaba outlet. Finally, seven other episodes which are available in another gauging station "Ain_Timedrine" in this basin were used to validate the hydrological model and test their applicability in the Mediterranean semi-arid context.

The results obtained after model calibration for the 7 flood episodes are presented in the Figure 9. The representation of events emphasizes that the model clearly reflects the underestimation of peaks in all episodes used; the recessions are too rapid and low flows too low. It is also remarkable that the simulations and observations are in very good agreement for 5 events (events: 1,2 , 3,5 and 7) and weakly for the other two events (events 4 and 6), showing ATHYS model accounting in the semi-arid climate. It should also be noted that the simulated mean flows are lower than the mean flows observed in most cases. However, the naked eye analyses are generally not sufficient to assess the quality of the simulations, so an evaluation using mathematical equations is necessary to ensure that our hydrological model has been successful in reproducing flows in the basin under study.

\section{Model evaluation}

The performance criteria of a hydrological model can be simple (ratio of simulated and observed water volumes), or computational in general inspired by statistical methods to standardize the comparison between the result of the simulation or of the forecast and observations (Clarke 1973)and some of the many available models are classified into four main groups. It is suggested that models with parameters estimated by computing the minimum of a least-squares objective function represent an application of well-known non-linear regression theory to situations in which the assumptions commonly made in this theory are seldom valid. The correction required is not the use of objective functions other than those based on sums of squares, but the use of more realistic assumptions concerning the stochastic structure of the model residuals. Interdependence between model parameters necessitates extensive exploration of the sum-of-squares surface in the neighbourhood of its minimum even when regression assumptions are valid: this is particularly true where the model is to be used to examine the likely effects of a proposed physical change to the catchment, since the complexity of such a change will not generally be represented by a change in one (or even some. From rains, we deduce flow rate estimates that we compare with observed flows, owing to the criteria called objective functions to facilitate the interpretation of the results obtained on many events.

In this study, several criteria have been retained in order to appreciate the capacities of the model to reproduce the watershed behavior that can be calculated automatically by the ATHYS at the end of the model running or calculated manually by the user using the application mathematical equations corresponding to each performance criterion.

The performance criteria calculated automatically by the model are as follows:

- Nash-Sutcliffe: Proposed by Nash (1969) and taken up by Nash and Sutcliffe (1970), this criterion is commonly used in hydrology as an objective function to evaluate the predictive power of hydrological models; it also reflects the image of the adequacy of the hydrological model and the set of parameters calibrated to the studied basins (Kouassi et al. 2013). The equation of the Nash-Sutcliffe criterion is written as follows:

$$
\text { Nash }=1-\frac{\sum_{\mathrm{i}=1}^{\mathrm{n}}(\mathbf{Q o b s}, \mathbf{i}-\mathbf{Q} \text { sim }, \mathrm{i})^{\wedge} \mathbf{2}}{\sum_{\mathrm{i}=1}^{\mathrm{n}}(\mathbf{Q o b s}, \mathbf{i}-\mathbf{Q o b s . m})^{\wedge}}
$$

Qobs, i- Observed flows at time step i, Qsim, - Simulated flow at time step i, Qobs.m - Average flow observed during the period,

$\mathrm{n}$ - Total number of time steps in the study period.

This expression tends to 1 when the calculated flow tends to the observed flow rate (table 1).

- Erreur quadratique moyenne (EQM): It constitutes the arithmetic mean of the squares of the discrepancies between forecasts and observations. It allows answering the question, "what is the magnitude of the error of the forecast", but does not indicate the direction 

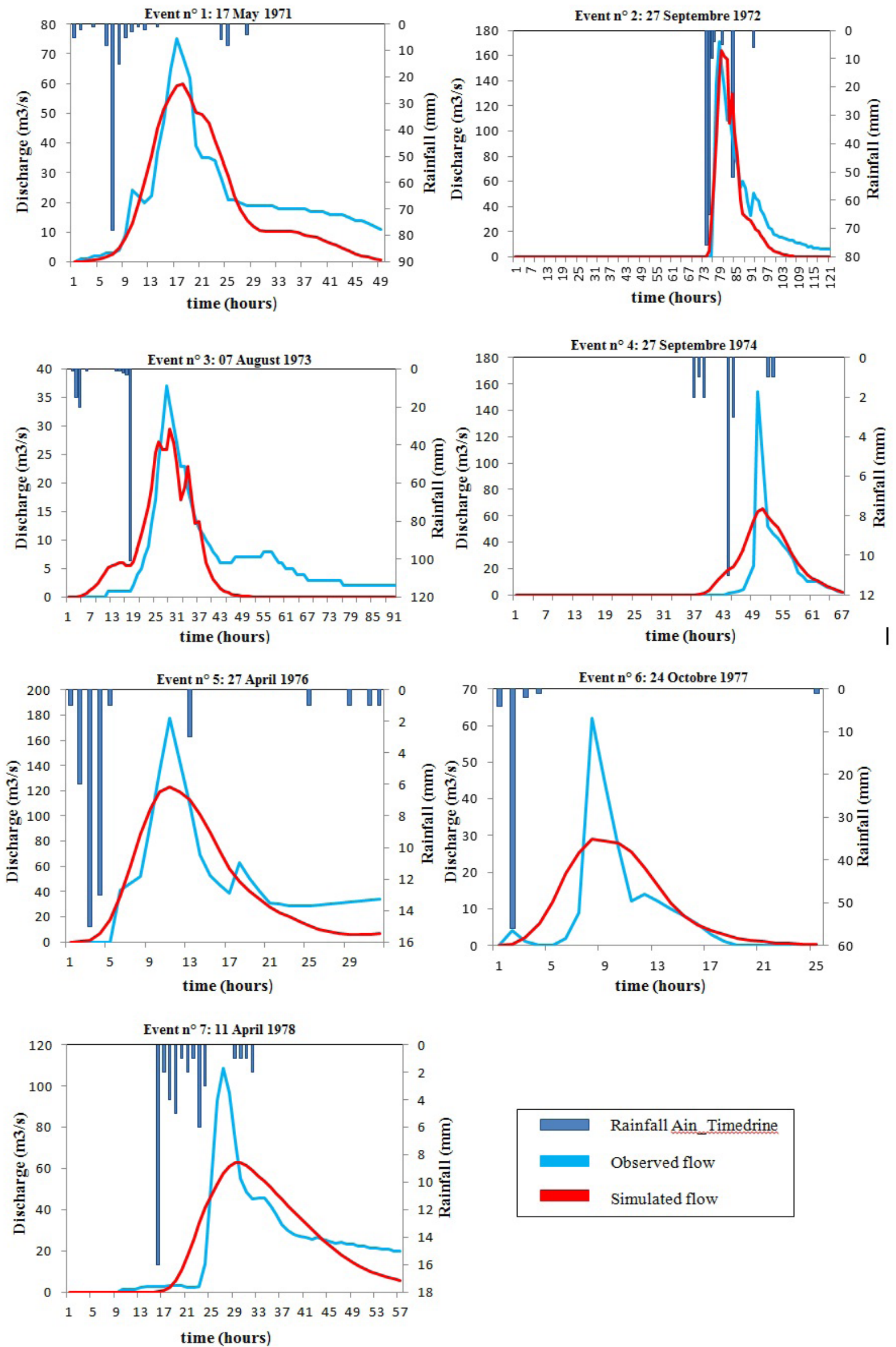

Figure 9. Simulated and observed flood hydrographs for the 7 most important events at Azzaba station (time step $=60 \mathrm{~min}$ ). 
Table 1. Interval of the most important performance criteria and their evaluation [from Moriasi (2007) modified]

\begin{tabular}{|l|c|c|c|}
\hline \multicolumn{1}{|c|}{ Performance Evaluation } & Nash Interval & RMSE Interval & PBIAS $\%$ Interval \\
\hline Very good & $0.75<$ Nash $<1.00$ & $0.00<$ RMSE $<0.50$ & PBIAS $< \pm 10$ \\
\hline Good & $0.65<$ Nash $<0.75$ & $0.50<$ RMSE $<0.60$ & $\pm 10<$ PBIAS $< \pm 15$ \\
\hline Satisfactory & $0.50<$ Nash $<0.65$ & $0.60<$ RMSE $<0.70$ & $\pm 15<$ PBIAS $< \pm 25$ \\
\hline No satisfactory & Nash $<0.50$ & RMSE $>0.70$ & PBIAS $> \pm 25$ \\
\hline
\end{tabular}

of the errors. Because it is a quantity squared, the EQM is more influenced by the large mistakes than by the smaller ones. Its range varies from 0 to infinity, the score of 0 being the perfect score. L'erreur quadratique moyenne $(\mathrm{EQM})$ is defined by the following mathematical equation:

$$
\mathbf{E Q M}=\frac{\sqrt{\sum_{\mathrm{i}=\mathbf{1}}^{\mathrm{n}(\mathbf{Q} \operatorname{sim}, \mathbf{i}-\mathbf{Q o b s}, \mathbf{i})^{2}}}}{\sum_{\mathrm{i}=\mathbf{1}}^{\mathrm{n}} \mathbf{Q o b s}, \mathbf{i}} * \sqrt{\mathbf{N}}
$$

Qobs, i - Observed flows at time step i, Qsim, i - Simulated flow at time step i, $\mathrm{N}$ - number of observation points.

- The arithmetic mean error (EAM): The arithmetic mean error which is the simplest of the precision references is commonly called "average error". Its range varies between zero and infinity, usually a value of zero means that the results are very efficient. The equation of the arithmetic error is written as follows:

$$
\mathbf{E A M}=\frac{\sum_{\mathrm{i}=\mathbf{1}}^{\mathrm{n}}|\mathbf{Q} \operatorname{sim}, \mathbf{i}-\mathbf{Q o b s}, \mathbf{i}|}{\sum_{\mathrm{i}=\mathbf{1}}^{\mathrm{n}} \mathbf{Q o b s}, \mathbf{i}}
$$

Qobs,i - Observed flows at time step i, Qsim,i - Simulated flow at time step i, $\mathrm{N}$ - number of observation points.

- Criterion CREC: This criterion is very little used compared to the other criteria above. Generally this criterion is very satisfactory if it is very close to zero. The mathematical function of the Crecific Criterion is written as follows:

$$
\operatorname{Crec}=\sum_{\mathbf{i}=\mathbf{1}}^{\mathbf{n}}\left(\mathbf{1}-\frac{\mathbf{Q s i m}, \mathbf{i}}{\mathbf{Q o b s}, \mathbf{i}}\right) * \sum_{\mathbf{i}=\mathbf{1}}^{\mathbf{n}}\left(1-\frac{\mathbf{Q o b s}, \mathbf{i}}{\text { Qobs.m }}\right)(13)
$$

Qobs, i- Observed flows at time step i,

Qsim, i-Simulated flow at time step i,

Qobs.m - Average flow observed during the period,

$\mathrm{N}$ - number of observation points.

The performance criteria most commonly used in hydrology, which are calculated manually by applying a set of mathematical equations, are as follows:
- The root mean square deviation (RMSD) or root mean square error (RMSE): A frequently used measure involves the differences between the values predicted by a model and the values observed (Janssen and Heuberger 1995)and the need for a wellestablished calibration strategy is obvious. Therefore a systematic approach for model calibration is proposed which is guided by the intended model use, and which is supported by adequate techniques, prior knowledge and expert judgement. The success of calibration will be primarily limited by the nature, amount and quality of the available data, in relation to the complexity of the model; additional limitations are the effectiveness of the applied techniques and the availability of time, manand computer power, adequate expertise and financial resources. These limitations will often preclude a unique calibrated model. As a consequence, calibration studies should provide information on the non-uniqueness and/ or uncertainty which will be left in the model parameters. It is given as:

$$
\operatorname{RMSE}=\sqrt{\frac{1}{\mathrm{n}} \sum_{\mathrm{i}=1}^{\mathrm{n}}\left(\mathbf{Q}_{\text {sim }, i}-\mathbf{Q}_{\mathrm{obs}, \mathrm{i}}\right)^{\mathbf{2}}}
$$

Where Qsim,i and Qobs,i are the modeled and observed values, respectively, and $\mathrm{n}$ is the number of data points.

- The Bias Error (PBIAS): This is the second criterion calculated in this study and it measures the model tendency to over- or underestimate the modeled flows by comparing them with the observed flows. This performance criterion varies between $-\infty$ and $\infty$, with a value of 0 for an unbiased model (Table 1). The PBIAS negative values indicate an overestimation of simulated flows, while PBIAS positive values reflect an underestimation of these flows. The model performance PBIAS is considered as satisfactory if PBIAS $< \pm 25 \%$ (Moriasi et al., 2007). This parameter is expressed in $\%$ : 


$$
\text { PBIAS } \%=\frac{\sum_{\mathbf{i}=\mathbf{1}}^{\mathbf{n}}(\text { Qobs, } \mathbf{i}-\mathbf{Q s i m}, \mathbf{i})}{\sum_{\mathbf{i}=\mathbf{1}}^{\mathbf{n}} \mathbf{Q}, \mathbf{o b s}, \mathbf{i}} * \mathbf{1 0 0}(15)
$$

Qobs,i - Observed flows at time step i,

Qsim, - Simulated flow at time step i,

$\mathrm{N}$ - number of observation points.

Table 2 presents the optimal parameters obtained after the calibration of the model as well as the objective functions calculated to evaluate the quality of the simulation for all events. In general, the performance criteria calculated for all flood events modeled by the coupled model SCS-LR show satisfactory or very good simulations, which indicates that the model applied in this study has succeeded in reproducing the flow rates at the outlet of our watershed.

From the in-depth analysis of these results, it can be seen that most of the errors (EAM, MSE, RMSE and $\mathrm{Crec}$ ) which calculate the differences between observed and modeled hydrographs tend towards zero, and also for the objective function "Nash-Sutcliffe", it can be noted that it varies between 0.57 and 0.89 as the maximum value. This shows the applicability of this model in the Mediterranean semi-arid context, especially for the calibration in the event mode.

Additionally, the objective function PBIAS is used to measure the tendency of the model to underestimate or overestimate the simulated flows. In turn, the positive values of this resulting criterion for events $1,2,3,5$ and 7 show the tendency of the coupled SCS-LR model of the ATHYS platform to underestimate flows in these episodes. On the other hand, the negative values of this criterion for the remaining other events indicate that the modeled flows are higher than the data values observed in most parts of the flood hydrographs.
The values of the parameters chosen for calibration and which have led to better simulations are generally realistic. The average value of the maximum capacity of the underground tank is about $370 \mathrm{~mm}$. This confirms that almost the entire basin is slightly affected by urbanization, and this is in good agreement with the reality of this basin dominated by the rural aspect.

\section{Model validation}

Generally speaking, this phase aims at validating the accuracy of the results, by checking if the calibrated model simulates correctly other series of data which are not used during calibration. In the final validation phase, the predicted values are compared with those observed to check if the objective function is reached. If this is not achieved for all of the datasets used for validation, the calibration assumptions may be re-examined by the hydrological model user (White and Chaubey 2006).

There are generally several methods for validating a hydrological model, but in this study the validation is carried out over a different period for the same basin and more precisely, the validation is based on the data available in the "Pont M'dez" station, which is located just in upstream of the outlet of our catchment.

In this study, we additionally used an equal number of events during the calibration phase in order to apply the simple split test. The validation was performed using the average values of the parameters obtained during the calibration phase to test the applicability of our hydrological model in our basin and in different periods of the year. Figure 9 shows the events used for validation.

In order to verify the performance of the model in runoff analysis at the short-term (1 hour), the results of the performance criteria and also

Table 2. Performance criteria values and optimal parameters for the calibration of the seven events at Azzaba station

\begin{tabular}{|c|c|c|c|c|c|c|c|c|c|c|c|c|}
\hline \multirow{2}{*}{ Episodes } & \multicolumn{4}{|c|}{ Optimal parameters } & \multicolumn{4}{|c|}{ Performance criteria } & \multirow{2}{*}{$\begin{array}{c}\text { Performance } \\
\text { evaluation }\end{array}$} \\
\cline { 2 - 14 } & S & W & Ds & V0 & K0 & EQM & EAM & Crec & RMSE & PBIAS & NSE & Very good \\
\hline $17 / 05 / 1971$ & 430 & 0,01 & 7,60 & 3,00 & 0,70 & 0,39 & 0,34 & 0,20 & 0,50 & 16,40 & 0,75 & Very good \\
\hline $27 / 09 / 1972$ & 538 & 0,01 & 9,80 & 4,40 & 0,70 & 0,43 & 0,36 & 0,46 & 0,34 & 19,2 & 0,89 & Good \\
\hline $07 / 08 / 1973$ & 490 & 0,01 & 8,00 & 2,60 & 0,70 & 0,63 & 0,57 & 0,72 & 0,57 & 26,9 & 0,68 & Satisfactory \\
\hline $27 / 09 / 1974$ & 300 & 0,01 & 9,01 & 4,51 & 0,70 & 0,95 & 0,56 & 1,97 & 0,61 & $-20,9$ & 0,63 & Good \\
\hline $27 / 04 / 1976$ & 280 & 0,01 & 6,53 & 4,48 & 0,70 & 0,40 & 0,34 & 0,18 & 0,51 & 9,8 & 0,74 & 0,54 \\
\hline $24 / 10 / 1977$ & 290 & 0,01 & 8,40 & 5,00 & 0,70 & 0,84 & 0,55 & 0,99 & 0,66 & $-17,6$ & 0,57 & Satisfactory \\
\hline $11 / 04 / 1978$ & 260 & 0,01 & 2,80 & 4,00 & 0,70 & 0,56 & 0,40 & 0,91 & 0,56 & 3,90 & 0,69 & Good \\
\hline Average & 370 & 0,01 & 7,45 & 4,00 & 0,70 & 0,60 & 0,45 & 0,78 & 0,54 & 5,39 & 0,71 & Good \\
\hline
\end{tabular}


Table 3. The values of the performance criteria and the average values of the parameters used to validate the model at the Ain_Timedrine station

\begin{tabular}{|c|c|c|c|c|c|c|c|c|c|c|c|c|}
\hline \multirow{2}{*}{ Episodes } & \multicolumn{5}{|c|}{ Optimal parameters } & \multicolumn{6}{c|}{ Performance criteria } & \multirow{2}{*}{$\begin{array}{c}\text { Performance } \\
\text { evaluation }\end{array}$} \\
\cline { 2 - 14 } & S & W & Ds & V0 & K0 & Crec & EQM & EAM & RMSE & PBIAS & Nash & Very good \\
\hline $27 / 10 / 1979$ & 370 & 0,01 & 7,45 & 4 & 0,7 & 0,46 & 0,34 & 0,28 & 0,32 & $-3,4$ & 0,89 & Good \\
\hline $11 / 05 / 1980$ & 370 & 0,01 & 7,45 & 4 & 0,7 & 0,84 & 0,53 & 0,42 & 0,52 & $-14,5$ & 0,73 & 0,73 \\
\hline $24 / 10 / 1981$ & 370 & 0,01 & 7,45 & 4 & 0,7 & 0,6 & 0,69 & 0,56 & 0,69 & 0,7 & 0,52 & Satisfactory \\
\hline $09 / 11 / 1983$ & 370 & 0,01 & 7,45 & 4 & 0,7 & 0,87 & 0,91 & 0,65 & 0,80 & 16,4 & $-0,07$ & Unsatisfactory \\
\hline $08 / 05 / 1990$ & 370 & 0,01 & 7,45 & 4 & 0,7 & 2,75 & 0,75 & 0,47 & 0,46 & 9,6 & 0,79 & Very good \\
\hline $09 / 05 / 1993$ & 370 & 0,01 & 7,45 & 4 & 0,7 & 0,29 & 0,46 & 0,36 & 0,40 & $-3,60$ & 0,84 & Very good \\
\hline $09 / 06 / 1996$ & 370 & 0,01 & 7,45 & 4 & 0,7 & 0,68 & 1,04 & 0,63 & 0,78 & 23,2 & 0,39 & Unsatisfactory \\
\hline Average & 370 & 0,01 & 7,45 & 4 & 0,7 & 0,93 & 0,67 & 0,48 & 0,57 & 4,06 & 0,58 & Satisfactory \\
\hline
\end{tabular}

optimal parameters obtained after the model calibration were presented in Table 3.

On the basis of the results predicted using rainfall data with an hourly time step (see Figure 9) and according to the performance criteria in Table 3, we can say that our model was validated and or reproduces the flows in our watershed well.

A very detailed analysis of the performance criteria values shows that the errors, regardless of their arithmetic or quadratic nature, are relatively lower, i.e. very close to zero, which implies that the results are very efficient and encouraging. In addition, the negative values of the PBIAS performance criterion in events 8,9 and 13 show that the model overestimates the flows in most points of these events, and for four other remaining events an underestimation of the flows is remarkable (positive PBIAS).

In addition, the analysis of the general pattern of the resulting hydrographs (see Figure 9), shows that the ATHYS model tends to underestimate point flows in all events.

\section{Hydrological modeling in continuous mode}

The ATHYS model is a distributed, conceptual model that can also be used for continuous modeling. The time step for the continuous mode is daily and it allows taking into account a large number of processes (including the infiltrations in the bed of the stream, the deep flows, etc). Most of the modules adopt a simple modeling formalism (tank model for the soil, day-degree type models for the growth of the vegetation) and some modules propose different formalisms, such as runoff according to the curve number method (S.C.S., 1972) used in this study.

Our goal of modeling the hydrological operation at the annual scale by the use of daily time steps is better analyzed the hydrological behavior and simulation of a long time in our basin. Figure 10 shows the period used for continuous mode modeling. The comparison of the general appearance of simulated and observed hydrographs allows us to say that the calibration is very strong by the hydrological model applied (see Figure 10).An in-depth analysis of base flows calculated and observed gave us information on the best restitution of these flows.

The comparison of peak flows shows that the model tends to underestimate flood peaks over the period used. In addition to the visual examination of the simulated hydrograph, various objective functions were used to measure the ability of the ATHYS rainfall-runoff model to replicate flows at the outlet of our watershed, and the results of applying these criteria were presented in Table 4.

The very important values of these performance criteria indicate a significant relationship between the observed flows and those calculated by the model. On the basis of the intervals of the performance parameters and their indications, we can notice for the Nash-Sutcliffe criterion that it is greater than 0.50 which means a satisfactory calibration of the period studied. Additionally, the negative value of the objective function PBIAS shows that the modeled flows are overestimated by coupling the SCS-LR model, and this is confirmed by the statistics made after calibration of this model to determine the runoff volumes relative to observed and simulated hydrographs which are $630547200 \mathrm{~m}^{3}$ and $876849558 \mathrm{~m}^{3}$. This does not allow us to say that the model also overestimates the point flows during the period used, so the visual treatment of the general appearance of the simulated hydrograph (Figure 10) shows a remarkable underestimation of these point flows. 

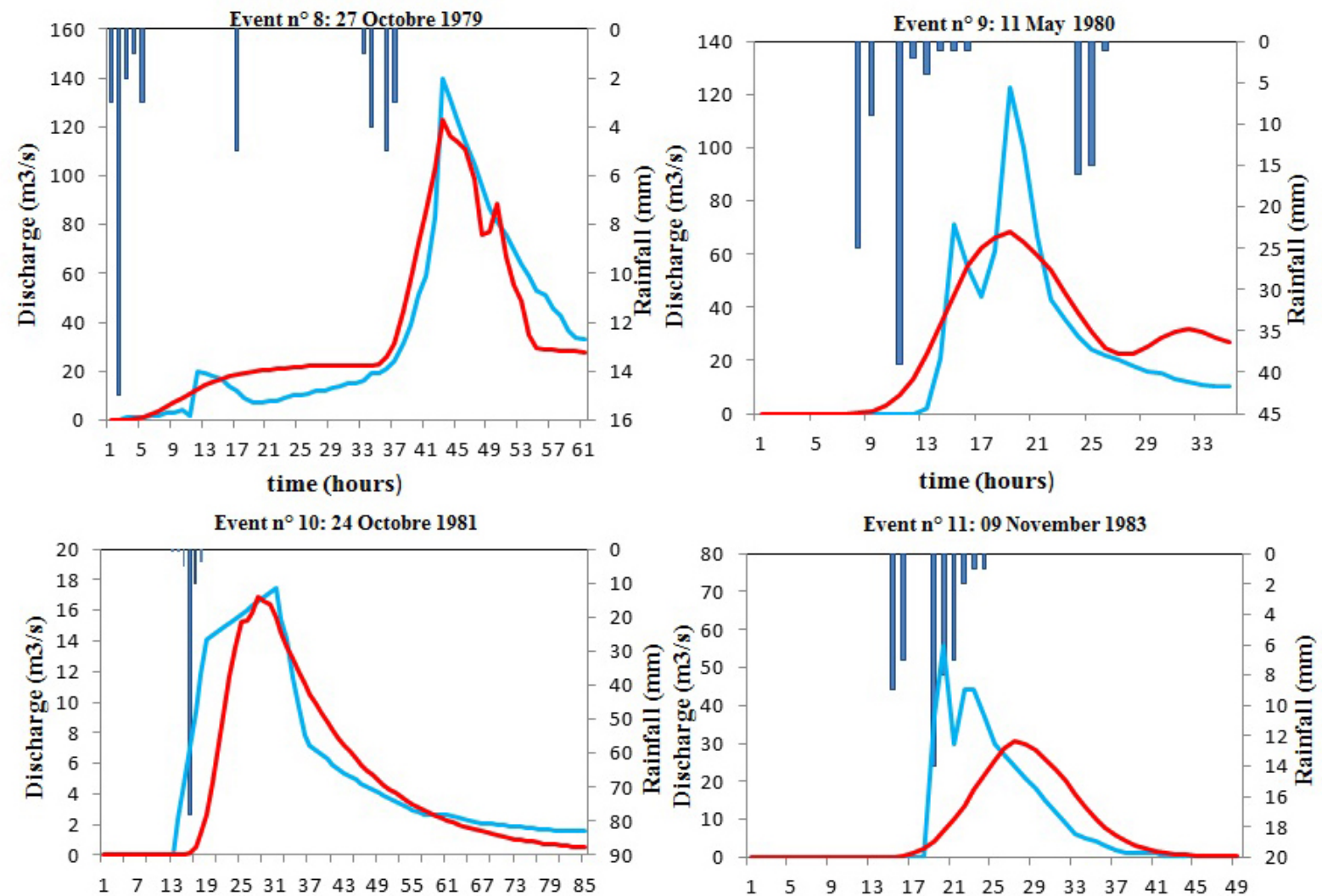

time (hours)

time (hours)
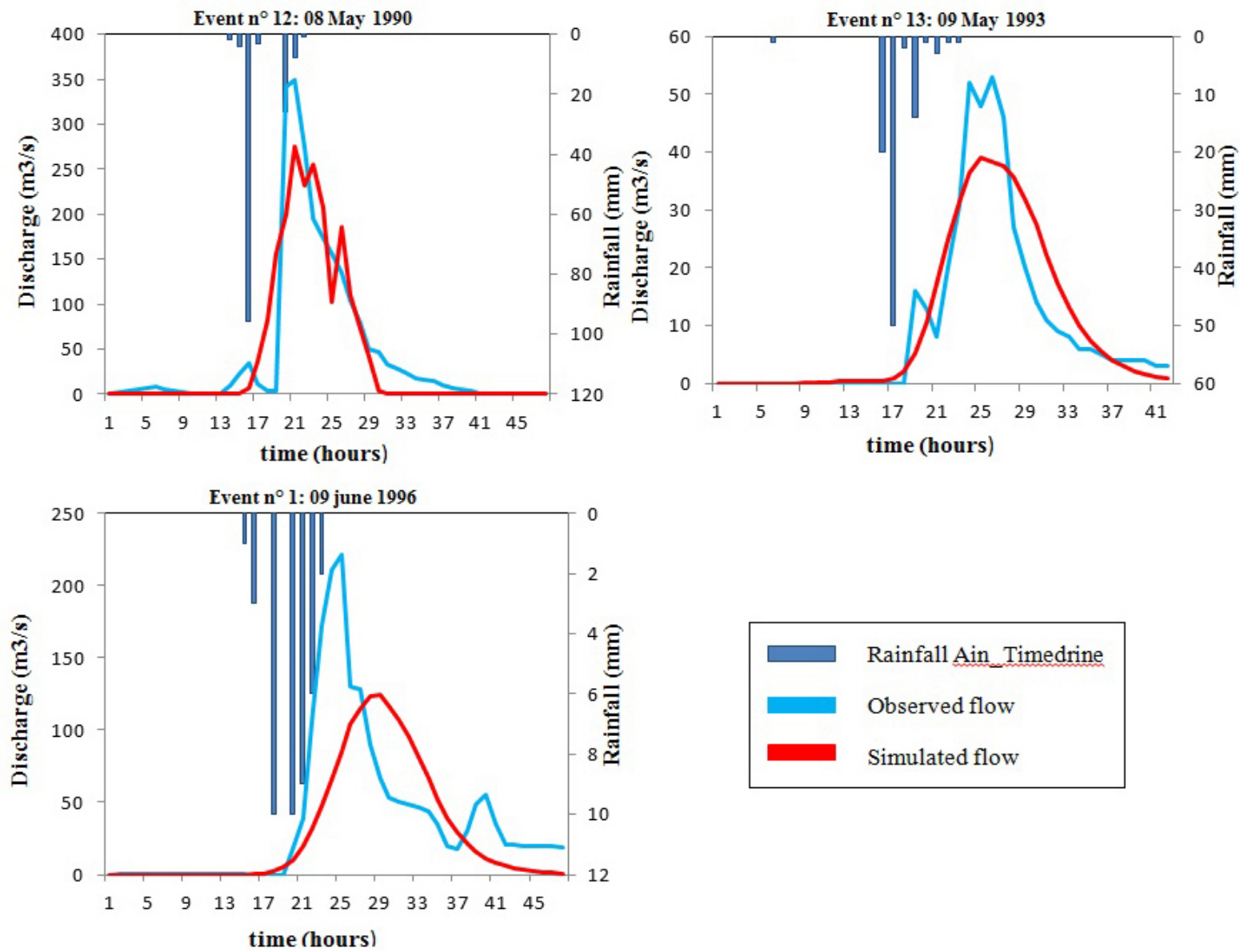

Figure 10. Illustration of the simulation of seven flood events used for model validation at Ain-Timedrine station (time steps $=60 \mathrm{~min}$ ) 
Table 4. Performance criteria values and optimal parameters selected for the calibration of a five-year period in the Azzaba station

\begin{tabular}{|c|c|c|c|c|c|c|c|c|c|c|c|c|}
\hline \multirow{2}{*}{ Period } & \multicolumn{4}{|c|}{ Optimal parameters } & \multicolumn{5}{c|}{ Performance criteria } & Performance \\
\cline { 2 - 12 } & S & W & Ds & V0 & K0 & EQM & EAM & Crec & RMSE & PBIAS & NSE & Sation \\
\hline $\begin{array}{c}01 / 01 / 2003- \\
31 / 12 / 2007\end{array}$ & 325 & 0,09 & 0,04 & 1,45 & 0,70 & 1,34 & 0,62 & 1,17 & 0,67 & $-38,80$ & 0,55 & Satisfactory \\
\hline
\end{tabular}

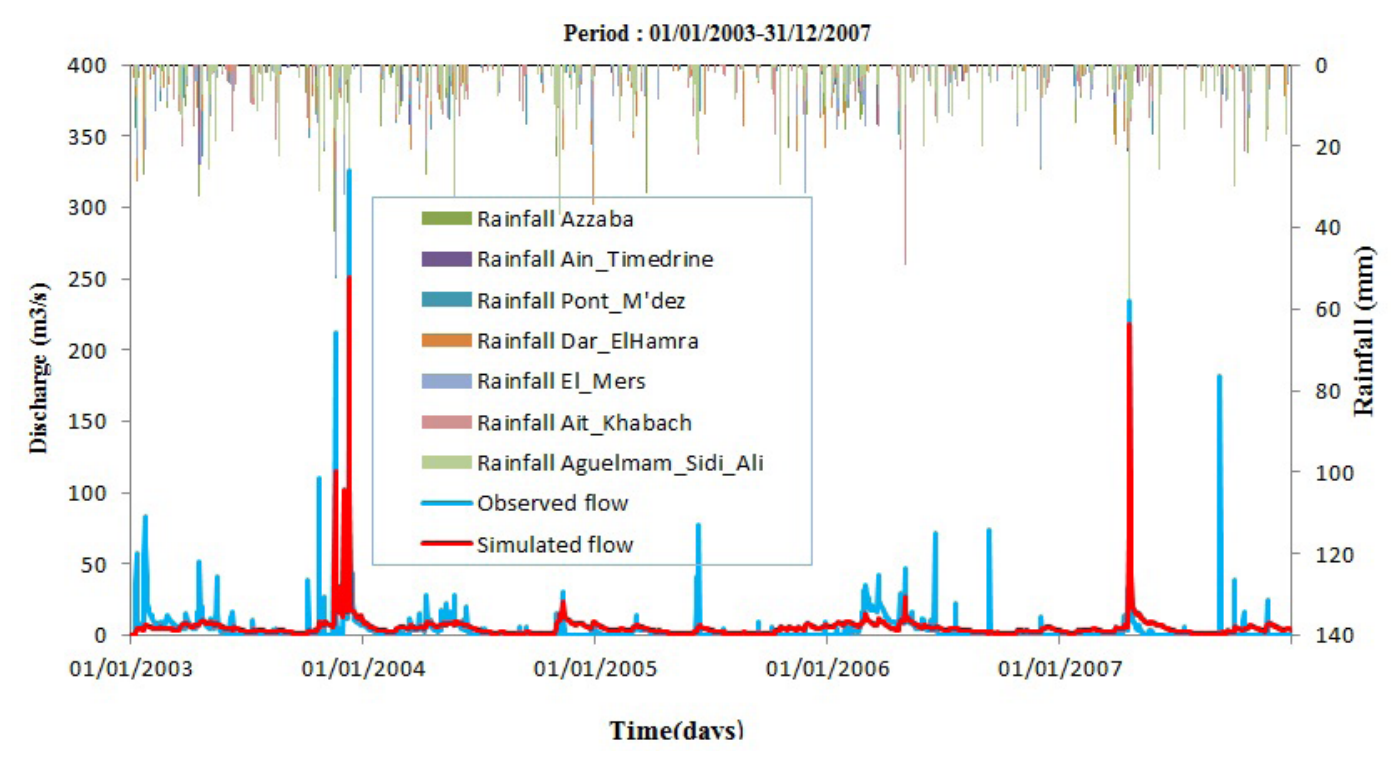

Figure 11. Simulated and observed Hydrographs throughout the years 2003-2007 at Azzaba station

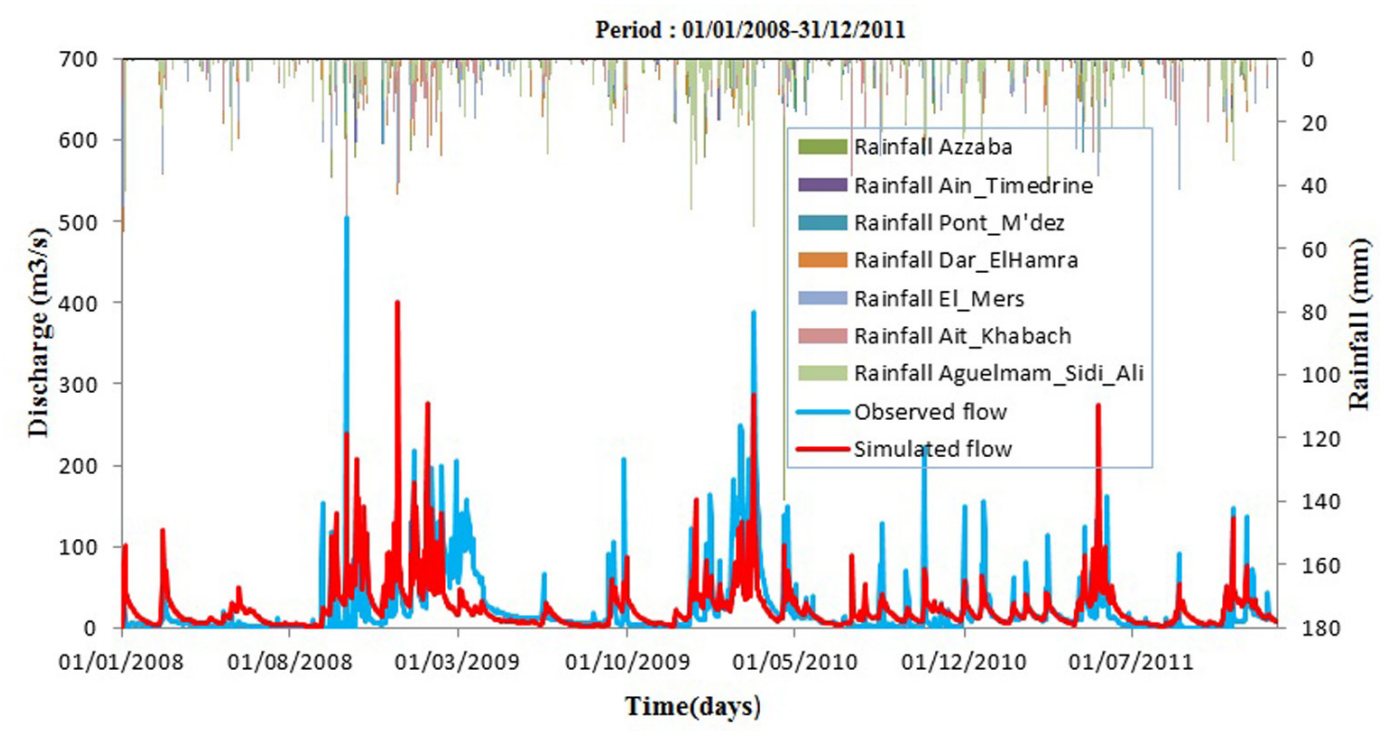

Figure 12. Simulated and observed Hydrographs throughout the years 2008-20011 at Azzaba station

For the optimal parameters obtained after calibration of the five-year period, it can be said that these values appear logical and respond to the physical properties of the watershed set.

\section{Model validation}

Validation is used to control the set of optimized parameters during the calibration period.
It must therefore be different to verify that this set of parameters can be transposed from one period to another. The period used in this study to validate the model is presented in the Figure 11. On the basis of Figure 11, it can be said that the model validation gives satisfactory results, with simulated flows comparable to those obtained by the ATHYS model, especially during low-water 
Table 5. The performance criteria values and average parameters used to validate the model with a four-year period at Azzaba station

\begin{tabular}{|c|c|c|c|c|c|c|c|c|c|c|c|c|}
\hline \multirow{2}{*}{ Period } & \multicolumn{4}{|c|}{ Optimal parameters } & \multicolumn{5}{c|}{ Performance criteria } & Performance \\
\cline { 2 - 11 } & S & W & Ds & V0 & K0 & EQM & EAM & Crec & RMSE & PBIAS & NSE & (vion \\
\hline $\begin{array}{c}01 / 01 / 2008- \\
31 / 12 / 2011\end{array}$ & 325 & 0,09 & 0,04 & 1,45 & 0,70 & 1,25 & 0,70 & 2,08 & 0,74 & $-3,80$ & 0,44 & Unsatisfactory \\
\hline
\end{tabular}

periods throughout the validation period, and also an accurate and very thorough analysis shows that base flows are correctly reproduced by the model.

Point flows or peak flows are always underestimated by the model, so there is a tendency to underestimate peaks in this period studied (observed flow rate max: $504 \mathrm{~m}^{3} / \mathrm{s}$ and calculated flow rate $\max : 401 \mathrm{~m}^{3} / \mathrm{s}$ ). Precise verification of the quality of our validation is required since some differences between observed and expected flows are not remarkable to the naked eye. Thus, it is necessary to carry out a performance study by calculating certain criteria that detect the small differences between simulation and observation, the values of these performance parameters are shown in Table 5.

According to this table, it can be noted that the Nash-Sutcliffe criterion is less than 0.5 and the errors (RMSE, EQM, EAM and CREC) are not very close to zero, which shows that the flows in the basin are poorly reproduced by the ATHYS model, especially during the periods of high flows. The poor flow simulation over this period results from the lack of rainfall data. This is due to the fact that flow forecasting is closely related to data quality and availability.

\section{CONCLUSIONS}

The ATHYS model has been selected for flood forecasting in this work for several reasons, including their applicability in the Mediterranean semi-arid context and the number of reduced parameters and also their distributed criterion that allows for consideration of physical processes and the good spatialization of the precipitation mesh by mesh in our basin, this platform is used for the first time in this basin and the performance results given by the model will of course encourage the future hydrologist to use this model in other basins in the same climatic context for better flood forecasting.

In the first step of this study, a modeling in event mode was elaborated to allow the event simulation of the rainfall-runoff relationship to simulate the hydrological behavior of the Azzaba watershed for a specific mode of operation, usually floods, without taking into account the specification of the history of previous conditions. The results obtained for the few calibration or validation events were very satisfactory in most cases, which shows the applicability of this model in the studied basin.

In general, the range of hydrological regimes explored is much more important in the case of continuous modeling, for which continuous modeling was also used in this work to continuously simulate the water balance and transfers at catchment scale over very long periods (typically annual or multi-year). The daily time step was used for continuous mode modeling. This time step is particularly relevant to better understand the hydrological functioning of the watershed, in especially the rapid changes in the flows following summer storms, and also to compare the flow rates calculated by the model with the flows measured in the gauging station.

Through comparison and analysis of results and simulations, decision makers can understand the hydrological behavior in the basin under consideration to better specify the boundaries of this study to allow for an assessment of availability and / or access to data to find much more relevant simulation results in the future, and also to increase the relevance and applicability of the ATHYS tool in other climatic contexts.

\section{Acknowledgements}

We noted that the data used to prepare this article were provided by the Department of Water Research and Planning (DRPE) of Morocco and all authors are grateful to this service.

\section{REFERENCES}

1. Andréassian, V., Perrin, C., \& Michel, C. 2004. Impact of imperfect potential evapotranspiration knowledge on the efficiency and parameters of watershed models. Journal of Hydrology, 286(1-4), 19-35. doi:10.1016/j.jhydrol.2003.09.030 
2. Andreassian, V., Perrin, C., Michel, C., Sanchez, I.U., \& Lavabre, J. 2001. Impact of imperfect rainfall knowledge on the ef $®$ ciency and the parameters of watershed models. Journal of Hydrology, 250, 206-223.

3. Archer, D. 1992. Walls of water. Circulation-British Hydrological Society Newsletter Society 44, 1-3.

4. Bentura, P.L.F., \& Michel, C. 1997. Flood routing in a wide channel with a quadratic lag-and-route method. Hydrological Sciences Journal, 42(2), 169-189. doi: 10.1080/02626669709492018

5. Berthet, L., Andreassean, V., Perrin, C., \& Javelle, P. 2009. How crucial is it to account for the Antecedent Moisture Conditions in flood forecasting? Comparison of event-based and continuous approaches on 178 catchments. Hydrol. Earth Syst. Sci., 13, 819-831.

6. Bouvier, C., \& Delclaux, F. 1996. ATHYS: a hydrological environment for spatial modelling and coupling with a GIS, in: Proceedings HydroGIS'96, Vienna, Austria, 19-28. IAHS Publication No. 235.

7. Bouvier, C., Fuentes Mariles, G., \& Dominguez Mora, R. 1994. MERCEDES, un modèle hydrologique d'analyse et de prévision de crues en milieu hétérogène. $4 p .$, 23è Journées de l'Hydraulique-Congrès de la SHF, Nîmes (France), Septembre, 257-260.

8. Ciarapica, L., \& Todini, E. 2002. TOPKAPI: A model for the representation of the rainfall-runoff process at different scales. Hydrological Processes, 16(2), 207-229. doi:10.1002/hyp.342

9. Clarke, R.T. 1973. A review of some mathematical models used in hydrology, with observations on their calibration and use. Journal of Hydrology, 19(1), 1-20. doi:10.1016/0022-1694(73)90089-9

10. Endreny, T.A., Wood, E.F., \& Lettenmaier, D.P. 2000. Satellite-derived digital elevation model accuracy: hydrological modelling requirements, 194(April 1999), 177-194.

11. Gaume, E., Livet, M., Desbordes, M., \& Villeneuve, J.P. 2004. Hydrological analysis of the river Aude, France, flash flood on 12 and 13 November 1999. Journal of Hydrology, 286(1-4), 135-154. doi:10.1016/j.jhydrol.2003.09.015

12. Janssen, P.H.M., \& Heuberger, P.S.C. 1995. Calibration of process-oriented models. Ecological Modelling, 83(1-2), 55-66. doi:10.1016/03043800(95) 00084-9

13. Kampf, S.K., \& Burges, S.J. 2007. A framework for classifying and comparing distributed hillslope and catchment hydrologic models. Water Resources Research, 43(5). doi: 10.1029/2006WR005370

14. Kouassi, A.M., Koffi, Y.B., Kouamé, K.F., \& Lasm, T. 2013. Application d'un modèle conceptuel et d'un modèle de réseaux de neurones artificiels à la simulation des débits annuels dans le bassin versant du N'zi-Bandama (Côte d'Ivoire ) Résumé, 9(1), 64-76.

15. Lhomme, J., Bouvier, C., \& Perrin, J.L. 2004. Applying a GIS-based geomorphological routing model in urban catchments. Journal of Hydrology, 299(3-4), 203-216. doi:10.1016/S00221694(04)00367-1

16. Mishra, S.K., \& Singh, V.P. 2003. Soil Conservation Service Curve Number (SCS-CN) Methodology. Kluwer Academic Publishers, Dordrecht, The Netherlands, ISBN 1-4020-1132-6.

17. Moriasi, D.N., Arnold, J. G., Liew, M. W. Van, Bingner, R.L., Harmel, R.D., \& Veith, T. L. 2007. Megsqaws, 50(3), 885-900.

18. Nash, J.E., \& Sutcliffe, J.V. 1970. River flow forecasting through conceptual models Part I - A discussion of principles. J. Hydrol. 10: 282-290.

19. Orlandini, S., \& Rosso, R. 1996. Diffusion wave modeling of distributed catchment dynamics. Journal of Hydrological Engineering 1(3): 101-113.

20. Saulnier, G.M., \& Le Lay, M. 2009. Sensitivity of flash-flood simulations on the volume, the intensity, and the localization of rainfall in the CévennesVivarais region (France). Water Resources Research, 45(10), 1-9. doi:10.1029/2008WR006906

21. SCS, 1956. National Engineering Handbook, Hydrology, Section 4, Soil Conservation Service, US Department of Agriculture, Washington DC.

22. Singh, V.P., \& Woolhiser, D.A. 2002. Mathematical Modeling of Watershed Hydrology. Journal of Hydrologic Engineering, 7(4), 270-292. doi: 10.1061/(ASCE)1084-0699(2002)7:4(270)

23. Tramblay, Y., Bouvier, C., Ayral, P.A., \& Marchandise, A. 2011. Impact of rainfall spatial distribution on rainfall-runoff modelling efficiency and initial soil moisture conditions estimation. Natural Hazards and Earth System Science, 11(1), 157-170. doi: 10.5194/nhess-11-157-2011

24. Vannier, O., Braud, I., \& Anquetin, S. 2014. Regional estimation of catchment-scale soil properties by means of streamflow recession analysis for use in distributed hydrological models. Hydrological Processes, 28(26), 6276-6291. doi: 10.1002/hyp.10101.

25. Wagener, T., Gupta, H., Yatheendradas, S., Goodrich, D., Unkrich, C., \& Schaffner, M. 2007. Understanding sources of uncertainty in flash-flood forecasting for semi-arid regions. IAHS Publication 313, (July), 204-212.

26. White, K.L., \& Chaubey, I. 2006. Sensitivity Analysis, Calibration, and Validation for a Multisite and Multivariable SWAT Model1. Journal of The American Water Resources Association, 41(5), 1077-1089. https://engineering.purdue. edu/ ichaubey/Pubs/White_Chaubey_JAWRA_ Oct05.pdf. 